\title{
ADOPTION OF MALAYSIAN PRIVATE ENTITIES REPORTING STANDARDS (MPERS): EXAMINING THE FEATURES OF THE STANDARDS AND CHALLENGES OF IMPLEMENTATION
}

\author{
Tanaraj Krishna \\ Faculty of Business and Management, Quest International University Perak, Malaysia \\ Charles Ramendran SPR \\ Faculty of Business and Finance, UniversitiTunku Abdul Rahman, Malaysia

\section{Zam Zuriyati Mohamad} \\ Faculty of Business and Finance, UniversitiTunku Abdul Rahman, Malaysia
}

\begin{abstract}
Malaysian Accounting Standard Board (MASB) has issued Malaysian Private Entities Reporting Standards (MPERS) on 14th February 2014. MPERS will be the single uniformed standards for all private entities in Malaysia effective from 1 st January 2016. In this context, this study intends to examine the perception of Malaysian accounting professionals regarding the desirable and undesirable characteristics of MPERS, the potential challenges of MPERS implementation. This study will examine the perceptions of the three different classes of Accountants, Accountants in public practice, Accountants in SMEs, and Accountants in academia in Malaysia by using quantitative methods with primary data collected from a survey questionnaire. The collected data will be analyzed using Structural Equation Modeling. The findings of this study are anticipated to provide useful and timely information to the MASB in making favorable provisions affecting the accounting practices, which in turn, will support the social and economic development in Malaysia. This study is expected to furnish some early evidences on the MPERS adoption in Malaysia besides bringing some fresh perspectives by examining the challenges of adoption of MPERS.
\end{abstract}

Key words: MPERS, SMEs, Malaysia, MASB 
Adoption of Malaysian Private Entities Reporting Standards (MPERS): Examining the Features of the Standards and Challenges of Implementation

Cite this Article: Tanaraj Krishna, Charles Ramendran SPR and Zam Zuriyati Mohamad, Adoption of Malaysian Private Entities Reporting Standards (MPERS): Examining the Features of the Standards and Challenges of Implementation, International Journal of Management, 11(6), 2020, pp. 2149-2166.

http://iaeme.com/Home/issue/IJM?Volume=11\&Issue=6

\section{INTRODUCTION}

Malaysian Private Entities Reporting Standards (MPERS) has been issued by the Malaysian Institute of Accountants (MIA) in 2014 to replace outdated Private Entities Reporting Standards (PERS). Malaysian Accounting Standard Board (MASB) adopted the International Financial Reporting Standards (IFRS) for small and medium-sized entities (SMEs) and tuned it to suit the Malaysian context. The standards serve as mandatory reporting standards for all Malaysian private entities starting $1^{\text {st }}$ January 2016 . This study intends to examine the perception of accounting professionals on the desirable and undesirable features of MPERS and the challenges of implementing MPERS. This move has resulted in a mixed response among market players, including business owners, accounting bodies, and also the government (Salin, 2017).

International Accounting Standards Board (IASB) issued IFRS for SMEs in 2019, intending to simplify the financial reporting of small and medium-sized entities. IASB emphasis that SMEs also in need of internationally comparable reporting standards like public limited companies even though SMEs are not traded in the public market. When SMEs interact with financial institutions, vendors, clients, credit rating agencies, venture capital firms and investors outside their home countries, SMEs and consumers of their financial statements will also benefit from globally comparative details on financial reporting. (IASB, 2009).

Malaysian SMEs plays a very significant role in the development of the national economy. They also are seen as backbone of the industrial development of Malaysia (Abd Razak et al., 2012; Abebe, 2014; Heimonen, 2012; Jamak et al., 2014). According to SME Corporations' report, it is stated that, $99.2 \%$ of the total entities in the three key economic sectors namely manufacturing, agriculture and services are consist of SMEs. Taking in to account the significant role playing by Malaysian SMEs in economic growth, the Malaysian government has introduce many business support initiatives through various agencies to support SMEs (National SME Development Council, 2016).

\subsection{Problem Statement and Research Significance}

In conjunction with the release of IFRS for SMEs by the IASB, at least 35 countries, inclusive of Malaysia is expected to adopt this new standard. Nevertheless, Malaysia has opted to adopt its own version, named MPERS - garnering mixed reactions from market forces such as business owners, accounting bodies and the government itself (Salin, 2017). The field of accounting is one that is fashioned by both political and economic powers. Thus, the symbiosis of politics and the markets - spurred by a decrease in communications and information-processing costs) — imminently causes an integration of financial reporting norms and practice (Phan, 2014).

Furthermore, there is little settled theory or evidence on which to build an assessment of the advantages and disadvantages of uniform accounting rules within a country. Studies has advanced over the past two decades for the harmonization and adoption of global accounting standards. At first, academics continued to discuss the harmonization of accounting standards and all of these findings were either subjective, concise or logically formulated (Saudagaran 
\& Diga, 1998; Chand \& Patel, 2008). Later research addressing the convergence of international accounting standards became more empirical in nature (Daske et al. 2008; Qu \& Zhang, 2010; Ghio \& Verona, 2015).

Commending the advantages and need for applying the Malaysian Financial Reporting Standards (MFRS) across big corporations listed on the stock exchange, the international business community seeks to push forth the same for non-listed companies. (Salin, 2017). It is a widespread belief that $99 \%$ of the companies formed in the world see their origins in nonlisted companies. In many developing countries such as Malaysia, non-listed companies are imperative for the economy to grow and develop through time. SMEs in countries like Germany, Japan and the United Kingdom (UK) contribute to more than 50\% of the nations' Gross Domestic Product (GDP) respectively (National SME Development Council, 2010). In Malaysia, $99 \%$ of business establishments comprise of SMEs, with their total contribution of $36.3 \%$ to the national GDP in 2015 (National SME Development Council 2016). As a result, the many advantages of financial reporting standards - currently held by listed companies and their associated parties - it is hoped that non-listed companies can also partake in these benefits. Along the years, there has been an increased requirement for financial reporting standards for non-listed companies, especially those which are globally comparable.

While the themes of international accounting harmonisation and convergence studies have been widely diverse, there has been a "methodological convergence" of descriptive over empirical studies over the 40 years (Baker \& Barbu, 2007, p.292). Except in the area of measurement of the extent of international harmonisation of accounting practices and their impact on share prices and returns, the international accounting convergence research, in general, has been criticised by Baker and Barbu (2007, p.293) who note that most international accounting research "lacked rigour and an adequate theoretical underpinning." Very few studies have attempted to hypothesise and measure the drivers of IFRS decision by transition and emerging economies (Vellam, 2012; Albu \& Albu, 2012) and even fewer studies examining the challenges and benefits of adoption of this new standard. This study will provide the early empirical evidence on examining the benefits and challenges by the adoption of MPERS in Malaysia.

\subsection{Research Questions}

RQ1. Do the perceived features of MPERS influence the adoption of MPERS?

RQ2. Do the perceived challenges of MPERS influence the adoption of MPERS?

\subsection{Research Objectives}

This study aims to evaluate the perceptions of accounting professionals (practitioners, accountants in SMEs and accounting academics) towards the features and implementation of MPERS as the new uniform accounting standards for SMEs and private entities in Malaysia on the following aspects:

This study explores how the features of MPERS influence adopting MPERS.

Next, this study investigates how challenges of adopting MPERS influencing the adoption of MPERS.

\section{LITERATURE REVIEW}

Generally, SMEs are exempt from statutory audit requirements and are subject to simplified accounting standards (IFC, 2011). With the full set of IFRS applied for publicly accountable entities, several arguments were raised by small entities about the complexity of applying full IFRS. Therefore, the need for a simplified set of accounting standards suitable for SMEs was 
Adoption of Malaysian Private Entities Reporting Standards (MPERS): Examining the Features of the Standards and Challenges of Implementation

extensively appealed by many jurisdictions (Perera \& Chand, 2015). Consequently, the IASB issued the IFRS for SMEs in July 2009, with the intention that they would be applied by SMEs around the globe. Similarly, in Malaysia, the MPERS is issued as the simplified version of MFRS by taking in to account the relevancy of the standards itself for the SMEs (MASB 2014). The MPERS features appear to play a significant role in the standards' adoption.

\subsection{SMEs Contributions}

Governments around the globe have recognised the importance of SMEs. Various countries had witnessed the role and contribution of SMEs to economic recovery during the economic crisis. During the economic crisis of the United States in the 1990s, Small companies have regenerated US firms global growth, creativity, and job creation (Audretsch, 2002). Similarly, in Malaysia, despite the economic climate, SMEs have recorded an overall $6 \%$ growth.

SMEs are more inclined than big firms to use manufacturing methods that are heavier on labour. As a result, they play a pivotal role in creating sustainable job opportunities, generating revenue and in the long run, the decline of poverty (Ploybut, 2012). Mclarty (2015) notes that the role of SMEs as a job-contributor is even more apparent in the private sector. SMEs strongly contribute to the shift from rural to industrial economies, incentivizing manufacturing operations to generate consistent revenue, thereby offering improved business growth (Kongkolo, 2010). SMEs also play a role in shifting the competitive landscape of resource management, a task that takes up productive capital across all socioeconomic levels. This, in turn, diversifies existing business structures that connect large and smaller businesses - a connection that is crucial for bringing in foreign direct investments (FDI) (Winter, 2016). These big businesses are constantly in search for reliable local vendors for their existing supply chains. In China's rapidly growing economy, Ploybut (2012) noted that the remarkable growth could be attributed to SMEs, as evidenced by their $40 \%$ contribution to the GDP, sector diversification, wealth size, and job growth.

Likewise, nations such as Korea, Japan and other industrialised economies have recognized the role of SMEs in providing jobs, decreasing poverty and improving community welfare. In Malaysia, the role of SMEs is no less important. Firstly, small and medium-sized businesses empower individuals to be more entrepreneurial, thus making the economics more diverse. Next, rapidly-growing production sectors such as cultivating maize and manufacturing find their origins in SMEs. By the process of job creation, SMEs can help slow the decline of poverty. Ultimately, though the social lens, SMEs are more efficient in managing resources than big corporations as they are seen as more empowering and considerate of their people's needs. (Rahim, Mahmood, \& Masrom, 2017).

It would be a rational proposition to say that SMEs can expand well in Malaysia's economy. Nevertheless, efforts thus far have largely focused on big corporations and have side-lined SMEs which can be regarded as the economic backbone of Malaysia. For instance, there are organisations that have been formed to promote trade practices - but choose focus their attention on larger businesses, effectively alienating SMEs and the special conditions that are necessary for them to thrive (Rasli, Johari, \& Muslim, 2017).

\subsection{Policy to Simplify Financial Reporting Requirements for SMEs}

Perceived ability of small and medium-sized businesses to produce economic and social benefits has driven many policymakers around the world to enact policy policies and programs to promote SME growth and development. It involves improving the business 
climate that will enable them to develop and contribute to the economy of the country at its fullest. Simplifications of financial reporting standards for SMEs were adopted in many countries and by foreign organisations in this regard.

Differential financial reporting was introduced in New Zealand, Malaysia and Sri Lanka, for example, after an improvement in quality and scope of the financial reporting requirements put excessive reporting burdens on SMEs (Devi, 2003). More recent recommendations by the European Commission on the elimination of the financial reporting requirements of micro-enterprises and the revision of the European Accounting Guidelines to reduce undue administrative pressures on micro and small enterprises in Europe were also adopted (EC, 2010).

To summarise, SMEs are essential to the productivity and economic growth of a nation. Differentiations in financial reporting standards for small, medium and large companies have been developed as part of policy policies to reduce regulatory pressures for SMEs and eliminate 'red tape' for enterprises to stimulate development. Examples provide a simplified set of accounting principles for SMEs, choice reporting and immunity from auditing. Nevertheless, it was proposed that attention should be extended not only to reporting costs but also to the advantages of these reporting conditions, before the legalization of financial reporting for SMEs (Jarvis \& Collis, 2003).

\subsection{Accounting Framework in Malaysia}

The history of accounting principles and reporting activities in Malaysia parallels its history as a country colonized by the British for more than 80 years, finally reaching independent in 1957. Malaysian standardised accounting standards were formed in the 1970s and gradually reached compatibility with IAS. The Malaysian Association of Certified Public Accountants and the Malaysian Institute of Accountants officially backed the IAS in 1977, and set to examine and personalise accounting standards to local requirements when issued by the International Accounting Standards Committee (IASC). Malaysia had successfully enacted a majority of the IAS principles, save for a few, by 1996. As the Financial Reporting Standards (FRS) framework was implemented in 2006, businesses had to adhere to the financial statements preparation and delivery standards laid out in the FRS, as released by MASB, starting $1^{\text {st }}$ January 2006. In November 2011, the MASB published the Malaysian Financial Reporting Standards (MFRS Framework), a newly approved accounting framework. The companies which are required to apply the MFRS system as specified by MASB are "Entities Other Than Private Entities shall apply the MFRS framework for annual periods beginning on or after 1st January 2012, with the exception of transitioning entities which are given options to continue with the old FRS framework". The MFRS framework was scheduled to be implemented by all businesses (other than private entities) on an annual basis, effective $1^{\text {st }}$ January 2012. Private entities are defined as companies established under the Companies Act 1965 that are not mandated to publish financial statements according to laws laid out by the Securities Commission Malaysia or Bank Negara Malaysia. Additionally, these private entities are not associates, subsidiaries, nor are they jointly handled by entities that are mandated to publish financial statements according to laws laid out by the Securities Commission Malaysia or Bank Negara Malaysia as well.

The PERS framework was expected to be applied exclusively by private entities, but they also have the liberty to apply the MFRS framework, effective $1^{\text {st }}$ January 2012. Nevertheless, the freedom of choice was only up till $31^{\text {st }}$ December 2012 as they were required to shift to the MFRS framework from $1^{\text {st }}$ January 2013 onwards (Accountants Today, 2012; Jebaratnam, 2012). On $14^{\text {th }}$ February 2014, the PERS was officially discontinued to pave the way for MPERS. 
Adoption of Malaysian Private Entities Reporting Standards (MPERS): Examining the Features of the Standards and Challenges of Implementation

\subsection{The Effects of desirable Features of MPERS on MPERS Adoption}

Ultimately, the core aim of MPERS is increase the comparability financial reporting between companies and nations, as well as to assist foreign investment and global consumers, due to being a coordinated set of accounting standards that has its origins in the IFRS For SMEs. Research has listed out the likeable aspects of the IFRS as superior quality, ease of comparibility and overall credibility. Proponents contend that that the IFRS leads over individual countries' local accounting guidelines. Several studies have noted changes in accounting standards since the adoption of IFRS, both mandatory and voluntary (Barth, Landsman \& Lang, 2008; Daske et al. 2008). Liu and Sun (2013) found that in the case of Canadian business entities, the mandated adoption of IFRS did not lead to increased efficiency in accounting. MPERS proponents also contend that with the higher standard of financial reporting statements, MPERS reporting serves to bolster comparability across sectors and countries (Brochet, Jagolinzer, \& Riedl, 2013). As a result, it is able to promote cross-frontier trade (Lee \& Fargher, 2010) and stock market incorporation (Saudagaran, 2008).

Prior researchers provided many reasons for a higher accounting quality in the financial statements under IFRS:

- They were originally designed for developed capital markets, and therefore, more relevant to investors (Ball 2006; Joos \& Leung, 2012);

- They reduce the alternative accounting methods, leading to lower-earning management (Jeanjean \& Stolowy, 2008; Liu \& Sun, 2013);

- They need higher quality measurement and recognition rules (De Franco, Kothari, \& Verdi 2010; Brochet, Jagolinzer, \& Riedl, 2013) that better represent the underlying economic status of a company, therefore more transparent than the local GAAP (Barth et al. 2011; Haller \& Wehrfritz, 2013);

- They require higher levels of disclosure and thus mitigate information asymmetries between companies and their shareholders (Lim, Yeo, \& Liu 2003; Lambert, Leuz, \& Verrecchia, 2012).

With the introduction of new disclosure policies under IFRS, companies stand to receive many benefits (Florou \& Pope, 2012). For instance, businesses would be able to have a higher asking price for goods (Ray, 2010) and acquire experienced workers (Naoum, Sykianakis, \& Tzovas, 2011) - by being able to stand out from its competitors through its receptiveness to change (Fox et al. 2013). On the same tangent, past studies have noted that "serious" IFRS adopters saw substantial decrease in their capital expenses and substantial changes in market liquidity, more than "label" adopters (Daske et al., 2009). Results related to IFRS is forecasted to be better for pioneer adopters in countries that already house higher-quality institutions and better convergence between domestic GAAP and IFRS (Ding et al. 2007). Integrity, performance and cost-effectiveness is constructed to evaluate this variable accordingly.

H1. Desirable features of MPERS influence the decision of MPERS adoption

\subsection{The Effects of undesirable Features of MPERS on MPERS Adoption}

It has been suggested that IFRS adoption can cause some unintended consequences. For example:

- Reducing accounting alternatives may result in a less true and faithful representation of the firms' underlying economics (Barth, Landsman, \& Lang, 2008); 
- As a result of the principle-based nature of IFRS (Hong, 2008), professional judgment may create opportunities for earning management (Brown, Collins, \& Thornton 1993; Chand, Patel, \& Patel, 2005); and

- Weak compliance frameworks for nations to follow will decrease the consistency of financial reporting, even though high-quality accounting requirements are enforced (Brown \& Tarca, 2007; Christensen, Hail, \& Leuz, 2011).

Many other scholars argued that the expense of capital raising might be raised in return due to substantial added reporting costs (Daske, 2006; Lambert, Leuz, \& Verrecchia, 2007; Hail \& Leuz, 2009; Karamanou \& Nishiotis, 2009; Armstrong et al. 2010). In addition to the potential disadvantages, previous authors also expressed some concerns regarding the costs of transitioning to IFRS. Lee, Walker, and Christensen (2008) expressed that transition costs may vary from firm to firm, and some may be common to all firms across many countries. For example, according to the report "EU implementation of IFRS and the Fair Value Directive" (ICAEW 2007), the ten common costs of conversion to IFRS include:

- IFRS project team,

- software and systems changes,

- additional external audit costs,

- external technical advice,

- training of staff,

- training other staff (such as IT staff, internal audit, and management),

- communications with third parties,

- tax advisory,

- additional external data costs, and

- costs arising from changes such as renegotiating debt covenants.

Issues on complexity, high upfront costs and other unpredicted effects have resulted in declined interests towards shifting from PERS to MPERS and have made some practitioners and regulators more apprehensive towards adopting MPERS. The negative impact, disadvantages and political apprehension items are constructed to assess this variable.

H2. Undesirable features of MPERS influence the decision of MPERS adoption.

\subsection{The Effects of challenges of MPERS on MPERS Adoption}

It is a widely accepted belief among economists, policymakers and business experts that SMEs are the backbone of economic growth (Mahembe, 2011). A healthy SME sectors serves to benefit the economy with increased job opportunities, increased manufacturing volumes, exports and driving innovation and spurring an entrepreneurial spirit. Mahambe (2011) elaborates that SMEs are the stepping stones towards industrialising and act as catalysts of achieving a country's growth goals. Due to SMEs sizeable impact on the Malaysia economy, it is crucial to incentivise them as it would lead to successful growth of the economy.

It is expected that companies that do not possess 'public accountability' and lodge general purpose financial statements for external users could adopt the IFRS for SMEs. The guidelines are available for other organisations seeking to prepare and publish accounts that live up to a 'fairly presenting' description under an accounting framework. This group of organisations would encompass close corporations, companies, sole traders, partnerships, and trusts where the trust deeds allow (IASB, 2007a). 
Adoption of Malaysian Private Entities Reporting Standards (MPERS): Examining the Features of the Standards and Challenges of Implementation

MPERS has simplifications that are tailored to the requirements of those who would use the SMEs' financial statements. Despite seeing some foundation based on MFRS, MPERS is an independent framework that operations isolated from the general MFRS.

According to IASB (2007c, p. 3), IFRS for SMEs or MPERS would offer these advantages:

- At a national and international scale, it would make financial information of SMEs more comparable

- Ease the implementation trans-border acquisitions and kickstarting planned mergers and agreements with foreign businesses

- Enhance the fiscal health of SMEs by helping them participate in global markets.

Even with the listed advantages, MPERS still has its share of threats such as the potential for expenses incurred in the adoption process surpassing the expected benefits. As a result, this has drawn mixed responses during discussions on abolishing local reporting standards in favour of international ones (Kennedy and Emmanuel, 2013). According to Poroy \& Sipahi (2007), the shift to MPERS may pose difficulty due to the low corporate level of SMEs and variation between taxation standards and MPERS. Riva and Salotti (2015) found that from the perspective of financial markets accessibility, SMEs are more inclined to independently raise funds (from within) the entity rather than rely on banks. Moreover, the study found an insignificant relationship between accounting information quality (disclosure) and the cost of banking credit.

Roberts and Sian (2006) posed a question on the suitability of MPERS for smaller businesses within the larger SME field, in their paper titled entitled "Micro-entity Financial Reporting: Perspectives of Preparers and Users". They cited lack of formal accounting education, lack of digital accounting systems, and lower literacy levels as potential barriers of producing sound financial information that adheres to IFRS, specifically in less developed nations. Lekhanya (2013) corroborated this by noting that "people working in rural SMEs in KZN (Kwazulu-Natal), including business owners/managers do not have accounting and financial management skills". Danie and Pieter (2011) also found that introducing IFRS has, in fact, made it harder for SMEs to follow accounting requirements.

In the transition process to a new reporting framework, MPERS it set to bring forth some issues for those involved such as preparers, regulators, auditors, and consumers. For regulators, the problem lies in deciding to which level should the national GAAP be similar to or dissimilar from IFRS (Heidhues \& Patel, 2008). This would permit researchers to see what adjustments are required in terms of hardware and the reporting software; and how much would the daily workload requirements change as well (AICPA, 2011). Additionally, handling public perception towards changes in financial statements poses another issue for firms set to adopt the standards (PWC, 2011). From an audit point of view, Deloitte (2008) contended that it is necessary for the employed staff to have the required expertise before their clients start the transition stage, but not too early that the knowledge becomes obsolete or is wasted from lack of use.

To make matters of introducing IFRS more complex, the IFRS is not yet finalised and changes are constantly being introduced (Fox et al., 2013) - thus marring the chances of a smooth transition to a full enforcement status under IFRS (Joshi, Bremser, \& Al-Ajmi, 2008). From an education perspective, some academics are sceptical if students should learn about IFRS and if experts are updated with current standards (Wong, 2004; Heidhues \& Patel, 2008). 
Ultimately, the potential obstacles and issues with MPERS adoption - especially those predicted by the stakeholders - pose a threat to the exercise of streamlining international accounting standards with that of domestic ones.

H3. Challenges of MPERS influence the decision of MPERS adoption.

\subsection{Research Framework}

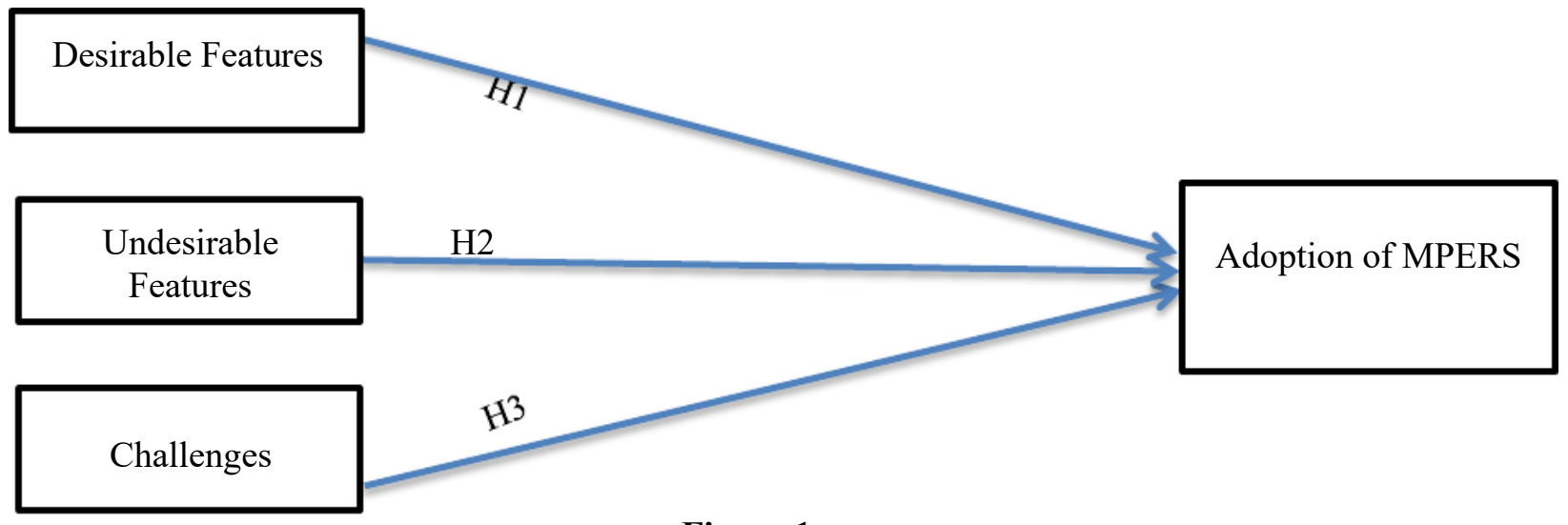

Figure 1

\section{RESEARCH METHODOLOGY}

In this study questionnaire were used to collect information. The questionnaires were sent to 285 audit firms, including small-medium practitioners (SMP) with a mixture of on-site questionnaire distribution and an online survey. SMP was included as they are playing an essential role in enhancing the growth of SMEs (IFAC,2014). Moreover, in this MPERS related study, the perspective of SMPs is most relevant as a preparator. MIA's has given special permission to distribute questionnaires during their MPERS associated training sessions. The survey questionnaires were distributed in a total of 12 training sessions in various places in Malaysia. Mainly accountants from SMEs and accountants in public practice were the attendees of the training sessions. Collection of survey data from accounting academics also were conducted in a mixture of on-site and online survey methods. The contact details of accounting lecturers were traced from the institution's staff directory. Then online survey questions were given to the majority of them. Academics from 10 universities participated in the survey.

PLS path modelling is a valid tool for structural equation modelling. According to Hair, Hollingsworth, Randolph, and Chong (2017) PLS-SEM can be used for the following four reasons: (1) the research objective is a confirmation of theory based on total variance, (2) the structural and measurement model is complex (many constructs, items, hypotheses), (3) the data was not normally distributed, and (4) the measurement of philosophy is in estimation with the composite factor model using total variance. Thus, in this research, PLS path is used due to the factors where the data was not normally distributed. 
Adoption of Malaysian Private Entities Reporting Standards (MPERS): Examining the Features of the Standards and Challenges of Implementation

\section{DATA ANALYSIS}

\subsection{Demographic Analysis}

Table 1 Respondent's Background

\begin{tabular}{|c|c|c|c|}
\hline Information & Frequency & Percentage & $\begin{array}{r}\text { Cumulative } \\
\text { Percentage }\end{array}$ \\
\hline \multicolumn{4}{|l|}{ Gender } \\
\hline Female & 150 & 61.7 & 61.7 \\
\hline Male & 242 & 38.3 & 100 \\
\hline Total & 392 & 100 & \\
\hline \multicolumn{4}{|l|}{ Age (Years) } \\
\hline $21-30$ & 173 & 44.1 & 44.1 \\
\hline $31-40$ & 119 & 30.4 & 74.5 \\
\hline $41-50$ & 72 & 18.4 & 92.9 \\
\hline $51-60$ & 16 & 4.1 & 96.9 \\
\hline Above 60 & 12 & 3.1 & 100 \\
\hline Total & 392 & 100 & \\
\hline \multicolumn{4}{|l|}{ Education Level } \\
\hline Bachelor & 265 & 67.6 & 67.6 \\
\hline Diploma & 38 & 9.7 & 77.3 \\
\hline Master & 72 & 18.4 & 95.7 \\
\hline PHD & 17 & 4.3 & 100 \\
\hline Total & 392 & 100 & \\
\hline \multicolumn{4}{|c|}{ Membership of Professional Bodies } \\
\hline ACCA & 115 & 29.3 & 29.3 \\
\hline ACCA and CPA Australia & 6 & 1.5 & 30.9 \\
\hline CIMA & 22 & 5.6 & 36.5 \\
\hline CPA Australia & 46 & 11.7 & 48.2 \\
\hline MIA & 100 & 25.5 & 73.7 \\
\hline MIA and ACCA & 28 & 7.1 & 80.9 \\
\hline MIA and CIMA & 5 & 1.3 & 82.1 \\
\hline MIA and CPA Australia & 19 & 4.8 & 87 \\
\hline MIA and MICPA & 1 & 0.3 & 87.2 \\
\hline MICPA & 9 & 2.3 & 89.5 \\
\hline MICPA and ACCA & 2 & 0.5 & 90.1 \\
\hline None & 4 & 1 & 91.1 \\
\hline Other & 35 & 8.9 & 100 \\
\hline Total & 392 & 100 & \\
\hline \multicolumn{4}{|l|}{ Experience (Years) } \\
\hline $3-5$ & 151 & 38.5 & 64.5 \\
\hline $6-10$ & 109 & 27.8 & 92.3 \\
\hline $11-15$ & 59 & 15.1 & 15.1 \\
\hline $16-20$ & 41 & 10.5 & 25.5 \\
\hline $21-25$ & 2 & 0.5 & 26 \\
\hline Over 20 & 30 & 7.7 & 100 \\
\hline Total & 392 & 100 & \\
\hline \multicolumn{4}{|l|}{ MPERS Knowledge } \\
\hline Excellent & 12 & 3.1 & 50.3 \\
\hline Good & 140 & 35.7 & 86 \\
\hline Average & 185 & 47.2 & 47.2 \\
\hline Poor & 36 & 9.2 & 100 \\
\hline Not at all & 19 & 4.8 & 90.8 \\
\hline Total & 392 & 100 & \\
\hline \multicolumn{4}{|c|}{ Level of MPERS knowledge required at work } \\
\hline Average & 155 & 39.5 & 39.5 \\
\hline Basic & 35 & 8.9 & 48.5 \\
\hline Excellent & 37 & 9.4 & 57.9 \\
\hline Good & 137 & 34.9 & 92.9 \\
\hline Not at all & 6 & 1.5 & 94.4 \\
\hline Not required & 18 & 4.6 & 99 \\
\hline Poor & 4 & 1 & 100 \\
\hline Total & 392 & 100 & \\
\hline \multicolumn{4}{|c|}{ Category of respondent } \\
\hline Accountant in Academic & 66 & 16.8 & 16.8 \\
\hline Accountant in Practice & 191 & 48.7 & 65.6 \\
\hline Accountant in SME & 135 & 34.4 & 100 \\
\hline Total & 392 & 100 & \\
\hline
\end{tabular}


Table 1 indicates that the bulk of respondents are male (242 individuals, 61.7 per cent) compared with females (150 individuals, 38.3 per cent). The data shows that the majority of them are aged between 21 and 30 years (173 individuals, 44.1\%), followed by an aged group of 31 to 40 years (119 individuals, 30.4\%) and 41 to 50 years ( 72 individuals, $18.4 \%$ ) respectively. This is logical as the majority of the accountants from the three categories are belongs to these age groups. Therefore, males are more likely to represent the accountants' group than females. Similarly, accountants from the age group of 21-30 are the highest number in accountants' fraternity. These are because this is the age group where the fresh graduates are entering the employment markets. Besides, the older ones in this profession will reach higher or managerial positions who are not many in our respondent list.

The level of education of respondents shows that the highest number of respondents had a bachelor's degree, which was $67.7 \%$. This is because many accounting graduates will pursue professional qualifications after they have completed their bachelor's degree. Respondents with a master qualification are the second in the list, which shows $18.4 \%$. These respondents are mainly from the category of accountants in academics where they will pursue masters after their first degree to allow them to become lecturers in higher institutions.

As the membership of a professional body playing a vital role in the accounting profession, it is essential to analyze the professional membership status of the respondents. Membership of ACCA has recorded a total of 115 members, which equivalent to $29.3 \%$. Some respondents have double memberships along with ACCA, such as membership of CPA Australia with ACCA (1.5\%), MIA membership with ACCA (7.1\%), and the last one is membership of MICPA with ACCA $(0.3 \%)$. In total, respondents with ACCA qualification are $38.4 \%$. The record in line with data that ACCA qualification is one of the important professional qualifications in Malaysia. It has more than 18 thousand members (ACCA, 2018) in Malaysia. Next, MIA membership has recorded a total number of 100 respondents. This means $25.5 \%$ of the respondents are from this category. As we discussed before, MIA is a regulatory body governs by accountants act 1967, which regulates the accounting profession.

Furthermore, MIA is the sole body issue audit license to the auditors in public practice. Therefore, most accountants in Malaysia will be a member of MIA. Apart from that, there are members of other professional bodies which relatively small in number compare to ACCA and MIA, such as CIMA (5.6\%), CPA Australia (11.7), and MICPA (0.5\%). There also respondents on the list without any membership, which amounting $8.9 \%$. The fresh graduates are needed three years of working experience to become a member of any professional body. This could be a possible reason to justify the non-member respondents.

In regards to experience level, the majority of the respondents are with the experience of three to five years, which shows $38.5 \%$ followed by respondents from the number years of experience of six to ten, which recorded $27.8 \%$. The numbers are in line with the prior analysis of age group, which shows the majority of the respondents are from 21 years old to forty years old.

The subsequent analysis is on the composition of the type of respondents. The majority of the respondents are accountants in practice or the auditors in public practice. The record shows $48.7 \%$ per cent of the respondents are auditors which followed by $34.3 \%$ of the category of accountants in SMEs. Lastly, accountants in academic shows an amount of $16.8 \%$ of the respondents are from the type. This is supported by MIA's statistics (MIA, 2019) that the majority of accountants are from Audit and followed by accountants from corporate, and only a small number of accountants are from academics. 
Adoption of Malaysian Private Entities Reporting Standards (MPERS): Examining the Features of the Standards and Challenges of Implementation

\subsection{Measurement Model}

The measurement model with reflective indicators was modelled using SmartPLS 3.2.6 (Ringle, Wende, \& Will, 2005). It was then evaluated through an examination process conducted on the reliability and validity of the items and constructs. Based on the rule of thumb, a measurement model has a satisfactory reliability of internal consistency when the composite reliability (CR) of each construct exceeds the threshold value of 0.708 (Hair, Hult, Ringle, \& Sarstedt, 2016). Furthermore, all of the CR values in this model were beyond 0.708. In addition, convergent validity was assessed by measuring the average variance extracted (AVE) values. As a result, it was shown that the AVE values for all constructs were beyond the threshold value of 0.50 , which indicated satisfactory convergent validity.

Table 2 Measurement Model

\begin{tabular}{|c|c|c|c|c|c|}
\hline Constructs & Items & Loadings & $\boldsymbol{\alpha}$ & $\boldsymbol{\rho}_{\mathbf{c}}$ & AVE \\
\hline & DF1 & 0.811 & & & \\
\hline & DF2 & 0.849 & & & \\
\hline DF & DF3 & 0.882 & 0.916 & 0.935 & 0.706 \\
\hline & DF4 & 0.850 & & & \\
\hline & DF5 & 0.761 & & & \\
\hline & DF6 & 0.881 & & & \\
\hline & UF1 & 0.787 & & & \\
\hline & UF2 & 0.788 & & & \\
\hline UF & UF3 & 0.752 & 0.868 & 0.897 & 0.592 \\
\hline & UF4 & 0.813 & & & \\
\hline & UF5 & 0.741 & & & \\
\hline & UF6 & 0.734 & & & \\
\hline & CH1 & 0.838 & & & \\
\hline CH & CH2 & 0.865 & & & \\
\hline & CH3 & 0.856 & 0.917 & 0.935 & 0.705 \\
\hline & CH4 & 0.805 & & & \\
\hline & CH5 & 0.860 & & & \\
\hline & CH6 & 0.824 & & & \\
\hline & AD1 & 0.708 & & & \\
\hline AD & AD2 & 0.824 & 0.728 & 0.846 & 0.648 \\
\hline & AD3 & 0.874 & & & \\
\hline
\end{tabular}

By evaluating the factor loading of each item, the reliability of the indicator could be determined. According to Hair, Ringle \& Sastedt (2011), the factor loading is required to exceed 0.708. In this study, all the item in the measurement recorded loadings which exceeded 0.70 . The loading values were ranged between as low as 0.708 and as high as 0.882 . The respective factor loadings are shown in Table 2 above. From the results, it is observed that the set of constructs and items in the research have reached satisfactory levels of reliability and validity in the measurement model.

Recent criticism of the weakness of the cross-loading method and the Fornell-Larcker test for testing the discriminant validity in several conditions led to the proposal that the HTMT ratio is used to determine the discriminating validity (Hair et al., 2017; Henseler, Ringle, \& Sarstedt, 2015). HTMT is the ratio of the mean correlations of all items in different constructs to the mean correlations of the average items which measure the same construct (Henseler et al., 2015). As such, this study also uses this recently developed approach to determine discriminant validity (see Table 3 ). 
Table 3 Results of HTMT ratio

\begin{tabular}{|c|c|c|c|c|}
\hline & DF & UF & CH & AD \\
\hline $\mathrm{DF}$ & & & & \\
\hline $\mathrm{UF}$ & 0.072 & & & \\
\hline $\mathrm{CH}$ & 0.154 & 0.557 & & \\
\hline $\mathrm{AD}$ & 0.421 & 0.178 & 0.372 & \\
\hline
\end{tabular}

HTMT ratio greater than 0.85 (Kline, 2011) suggests a discriminant validity issue. Table 3 indicates all ratios are under 0.85 . Therefore, it is claimed that there is no discriminant validity issue between all the structures in the measurement models. As all criteria of convergent validity and discriminant validity have been satisfied, this review continues for the structural model evaluation in the next section.

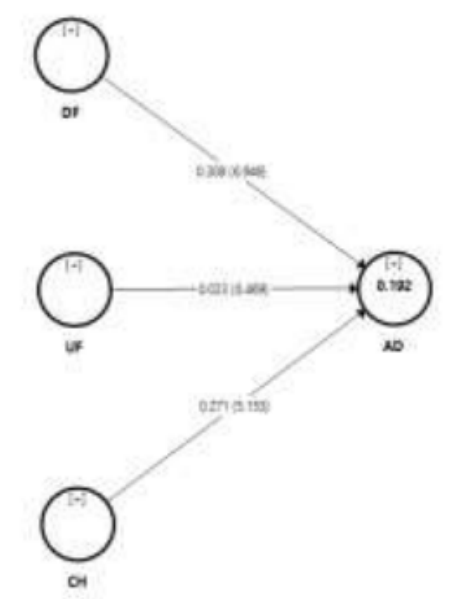

Figure 2 Structural Model

Table 4 Results of hypothesis testing

\begin{tabular}{|c|c|c|c|c|c|c|c|c|c|c|c|}
\hline Hypothesis & Relationship & $\begin{array}{c}\text { Std. } \\
\text { B }\end{array}$ & Std. Error & t-value & Decision & $2.50 \%$ & $97.50 \%$ & VIF & $\mathbf{R}^{2}$ & $\mathbf{f}^{2}$ & $\mathbf{Q}^{2}$ \\
\hline H1 & $\mathrm{DF}>\mathrm{AD}$ & 0.308 & 0.044 & $6.946 * *$ & $\mathrm{~S}^{*}$ & 0.211 & 0.386 & 1.024 & & 0.115 & \\
\hline $\mathrm{H} 2$ & $\mathrm{UF}>\mathrm{AD}$ & 0.023 & 0.050 & 0.469 & NS* & -0.102 & 0.104 & 1.298 & 0.192 & 0.001 & 0.120 \\
\hline H3 & $\mathrm{CH}>\mathrm{AD}$ & 0.271 & 0.053 & $5.153 * *$ & $\mathrm{~S}^{*}$ & 0.169 & 0.374 & 1.324 & & 0.069 & \\
\hline$* * \mathrm{p}<0.01$ & & & & & & & & & & & \\
\hline
\end{tabular}

*S-Supported **NS-Not supported

\subsection{Common Method Bias}

Common Method Bias (CMB) may post a threat to the validity of the results - in part due to the 'self-reported' nature of the data that has been acquired. A comprehensive collinearity test was conducted to identify if any constructs had variance inflation factor (VIF) values of at least 3.3 (Kock and Lynn, 2012). CMB was found to have no serious impact on this study as the results indicated the VIFs for the constructs ranged from 1.13 to 1.46.

\subsection{Structural Model}

Examining the structural model would require one to look at R-Squared $\left(\mathrm{R}^{2}\right)$ values, beta coefficients and t-values (Hair et al., 2014). In this study, the bootstrapping technique was used with 5000 resamples to obtain the t-values. Moreover, the predictive relevance $\left(\mathrm{Q}^{2}\right)$ coefficient and effect size $\left(\mathrm{f}^{2}\right)$ (Hair et al. 2014) was also found in this study. Sullivan and Feinn (2012) wrote that a p-value was useful to reveal the existence of an effect but not the magnitude of it. When it comes to reporting and interpreting results, the substantive 
significance (effect size) and statistical significance (p-value) both have to carefully examined and reported (p.279). Hahn and Ang (2017) have outlined some of the best practices in reporting quantitative results such as using effect size approximations, replicating the experiment, using confidence intervals, Bayesian methods, likelihood ration or Bayes factors, and decision-theoretic modeling.

As suggested we have included effect sizes and confidence intervals as part of our reporting (see Table 4). Desirable Features $\left(\beta=0.308 ; \mathrm{t}=6.964, \mathrm{p}<0.01, \mathrm{f}^{2}=0.115\right)$ and challenges $\left(\beta=0.271 ; \mathrm{t}=5.153, \mathrm{p}<0.01, \mathrm{f}^{2}=0.069\right)$ were significant while undesirable features $\left(\beta=0.023 ; \mathrm{t}=0.496, \mathrm{p}>0.01, \mathrm{f}^{2}=0.01\right)$ was insignificant predictor of adoption of MPERS. This study recorded the minimum value of $\mathrm{R}^{2}>0.10$ as suggested by (Falk \& Miller, 1992; Raithel, Sarstedt, Scharf, \& Schwaiger, 2012). At least 10\% variation in the dependent variable can be explained by the independent variable.

$\mathrm{Q}^{2}$ examines whether a model accurately predicts data not used in the estimation of model parameters (i.e., out-of-sample predictive power or predictive relevance) (Hair, Hult, et al., 2017). The measure of a model's predictive power recorder at 0.12 . Hence, the model is relevant as it is recorded $>0$ as suggested by (Fornell \& Cha, 1994; Hair et al., 2014).

\section{DISCUSSION AND IMPLICATIONS OF THE STUDY}

\subsection{Discussion}

In this study, we examine the effect of desirable features and undesirable features of MPERS and the challenges of implementation MPERS in the adoption of MPERS. As predicted, the construct of desirable features and challenges of MPERS influence the decision of MPERS adoption in Malaysia. This is in line with the findings of the study by Lekhanya (2013) and Danie and Pieter (2011), who note that the implementation of the International Financial Reporting Standards has made it harder for SMEs to comply with accounting requirements. On the different note, the findings support research on the effects of IFRS adoption, in which comparability and transparency were used to show the perceived desirable features of IFRS (De Fond et al. 2010). Furthermore, the findings reinforce the current literature that improvements in accounting principles generate beneficial economic implications such as reducing capital costs $(\mathrm{Li}, 2010)$, capital investment performance (Sun, 2006), and stock market liquidity (Daske et al. 2013).

Whereas the relationship between the undesirable features of MPERS and adoption of MPERS recorded as insignificant. Most respondents perceived that the undesirable features of MPERS that influence the adoption of MPERS could be 'too complicated for SMEs' and 'cost overweight the benefits. Many of the perceived that the benefits from the adoption of MPERS could not cover the cost of implementation of MPERS (Ionascu et al. 2017). A high percentage of the respondent also perceived that the MPERS is too complicated for the use of SMEs. This statement contradicts with the study by Salin, (2017), the organization is also able to save and reduce expenses involved in the national planning and implementation of standards, such as MPERS.

The MASB has made the MPERS as compulsory standard to adopt by all SMEs without fail. The mandatory requirement could be one of the reasons for undesirable features not influencing the adoption of MPERS. Somehow all the SMEs registered in Malaysia are required to follow the new standards regardless of the disadvantages. Even though the undesirable features and adoption do not show a significant relationship, it gives alarm to the policymakers on the undesirable features and disadvantages. 


\subsection{Implications of the Study}

In this study, a different alternative structural model analyzing factors influencing the national level adoption using structural equation models is discussed. It was proposed that the institutional pressures influence the decision of MPERS adoption, and it was further suggested that the decision of adoption influenced by the desirable features of MPERS, undesirable features of MPERS, and challenges of adoption. The thesis adopted a two-stage approach, which consists of confirmatory factor analysis and structural equation modeling. This research is a new contribution in the area of accounting regulation or reporting standards, as no other studies of this type were found before.

The research also contributes to the accounting standards literature by analyzing the perception of the significant issues related to the importance and applicability of MPERS adoption in the Malaysian's market context. This research is among the first empirical analysis in the context of Malaysia, which focuses on these issues. Additionally, the analysis is using advanced statistical techniques to address these research problems.

\section{RECOMMENDATION FOR FUTURE STUDIES}

The thesis served as the basis for further research. It is recommended to conduct further research to validate that interest constructs are always helpful and significant when MPERS is implemented in different circumstances (pre and post-adoption). It is proposed to have a study on evaluating the performance of the SMEs on post-adoption of MPERS is needed to quantify the favorable or unfavorable effect on the financial performance of SMEs.

In comparison, the relationships between the individual respondents' personal characteristics (such as employment, professional memberships, work experience) and aspects of MPERS acceptance were ignored. Such relationships may be explored in future research for a better understanding. Additionally, a variety of other methodologies may be used to offer insights into the relationship of different dimensions beyond those capable of structural equation modelling. Interviews and case studies could be used.

Future work should also be undertaken to supplement the results of this study by investigating how categories of respondents other than accountants, such as investors, financial firms, institutional lenders, regulatory agencies, viewed and used MPERS. Potential studies may also examine how accounting practices are influenced by improvements in every aspect. The literature provides comprehensive study resources from an institutional perspective to address the dynamic transition of the accounting profession. For example, future studies might investigate the development of the accounting profession in transition economies and accounting education.

The initiatives of the IASB in various research projects aimed at addressing accounting challenges posed by firms in developed economies are possible. It is also understood that the IASB is implementing a streamlined version of IFRS for small and medium-sized enterprises (SMEs) from those programs. However, the gap between the complexities of IFRS for SMEs and the actual needs of SMEs still persists in developed and developing markets and is challenging to cross. Future work may further investigate the importance of the nature of IFRS for small and medium-sized businesses, and the applicability of these criteria for SMEs is in developed countries such as Malaysia.

\section{REFERENCES}

[1] Salin, A. S. A. P. (2017). Malaysian Private Entities Reporting Standards-Benefits and Challenges to SMEs. International Journal of Academic Research in Business and Social Sciences, 7(11), 1302-1320. 
Adoption of Malaysian Private Entities Reporting Standards (MPERS): Examining the Features of the Standards and Challenges of Implementation

[2] Hanefah, H. M. M., \& Singh, J. (2012). Convergence towards IFRS in Malaysia: Issues, challenges and opportunities. International Journal of Business, Economics and Law, 1(2), 85-91.

[3] Ngah, R., \& Ibrahim, A. R. (2012). The relationship of intellectual capital, innovation and organizational performance: A preliminary study in Malaysian SMEs. Advances in Global Business Research.

[4] Abebe, M. (2014). Electronic commerce adoption, entrepreneurialorientation and small- and medium-sized enterprise (SME)performance. Journal of Small Business and Enterprise Development,21(1), 100-116

[5] Heimonen, T. (2012). What are the factors that affect innovation in growingSMEs? Europeran Journal of Innovation Management, 15(1), 122-144.

[6] Jamak, A. B. S. A., Ali, R. M. M., \& Ghazali, Z. (2014). A BreakoutStrategy Model of Malay (Malaysian Indigenous) Micro-entrepreneurs. Procedia - Social and Behavioral Sciences, 109(0),572-583.

[7] Phan, P.H., Wong, P.K., \& Wang, C.K. (2002). Antecedents to Entrepreneurship among University Students in Singapore: Beliefs, Attitudes andBackground. Journal of Enterprising Culture, 10(2), 151-174.

[8] Saudagaran, S. M., \& Diga, J. G. (1998). Accounting harmonization in ASEAN: Benefits, models and policy issues. Journal of International Accounting, Auditing and Taxation, 7(1), 21-45.

[9] Li, R., Fan, W., Tian, G., Zhu, H., He, L., Cai, J., ... \& Zhang, Z. (2010). The sequence and de novo assembly of the giant panda genome. Nature, 463(7279), 311-317.

[10] Ghio, A., \& Verona, R. (2015, June). Accounting harmonization in the BRIC countries: A common path?. In Accounting Forum (Vol. 39, No. 2, pp. 121-139).

[11] Baker, C. R., \& Barbu, E. M. (2007). Trends in research on international accounting harmonization. The International Journal of Accounting, 42(3), 272-304.

[12] Vellam, I. (2012). The adoption of IFRS in Poland: an institutional approach (Doctoral dissertation, University of Greenwich).

[13] Perera, D., \& Chand, P. (2015). Issues in the adoption of international financial reporting standards (IFRS) for small and medium-sized enterprises (SMES). Advances in accounting, 31(1), 165-178.

[14] Fuchs, F., Geisendorf, M., MASb, D. I. F., \& Bürgi, M. (2014). Development of a Method to Evaluate Primary Stability and Micro-Motion. Poster presented at International Association for Dental Research (IADR), Cape Town, South Africa.

[15] Audretsch, D. B., \& Fritsch, M. (2002). Growth regimes over time and space. Regional studies, 36(2), 113-124.

[16] Devi, L., Ptasinski, K. J., \& Janssen, F. J. (2003). A review of the primary measures for tar elimination in biomass gasification processes. Biomass and bioenergy, 24(2), 125-140.

[17] Köhler, E. C. (2010). Theories of state formation. In Egyptian archaeology (pp. 36-54). WileyBlackwell, Wiley.

[18] Jarvis, R., \& Collis, J. (2003). IFRSs and differential reporting.

[19] Jebaretnam, S. (2012, March 28). Getting up to speed with salient features of the updated MFRS and Malaysia's dual financialreporting framework. Kuala Lumpur: The Malaysian Institute of Accountants. 
[20] Ball, R. (2006). International Financial Reporting Standards (IFRS): pros and cons for investors. Accounting and business research, 36(sup1), 5-27.

[21] Joos, P. P., \& Leung, E. (2012). Investor perceptions of potential IFRS adoption in the United States. The Accounting Review, 88(2), 577-609.

[22] Jeanjean, T., \& Stolowy, H. (2008). Do accounting standards matter? An exploratory analysis of earnings management before and after IFRS adoption. Journal of accounting and public policy, 27(6), 480-494.

[23] Brochet, F., Jagolinzer, A. D., \& Riedl, E. J. (2013). Mandatory IFRS adoption and financial statement comparability. Contemporary Accounting Research, 30(4), 1373-1400.

[24] Sullivan, J. L., Juhasz, B. J., Slattery, T. J., \& Barth, H. C. (2011). Adults' number-line estimation strategies: Evidence from eye movements. Psychonomic bulletin \& review, 18(3), 557-563.

[25] Haller, A., \& Wehrfritz, M. (2013). The impact of national GAAP and accounting traditions on IFRS policy selection: Evidence from Germany and the UK. Journal of International Accounting, Auditing and Taxation, 22(1), 39-56.

[26] Lim, C. Y., Yeo, G. H., \& Liu, C. S. (2003). Information asymmetry and accounting disclosures for joint ventures. The International Journal of Accounting, 38(1), 23-39.

[27] Lambert, R. A., Leuz, C., \& Verrecchia, R. E. (2012). Information asymmetry, information precision, and the cost of capital. Review of finance, 16(1), 1-29.

[28] Barth, M. E., Landsman, W. R., \& Lang, M. H. (2008). International accounting standards and accounting quality. Journal of accounting research, 46(3), 467-498.

[29] Brown, G. A., Collins, R., \& Thornton, D. B. (1993). Professional judgment and accounting standards. Accounting, Organizations and Society, 18(4), 275-289.

[30] Brown, P., \& Tarca, A. N. N. (2007). Achieving high quality, comparable financial reporting: A review of independent enforcement bodies in Australia and the United Kingdom. Abacus, 43(4), 438-473.

[31] Di Pietra, R., Evans, L., Chevy, J., Cisi, M., Eierle, B., Jarvis, R., \& European Accounting Association's Financial Reporting Standards Committee. (2008). Comment on the IASB's exposure draft 'IFRS for small and medium-sized entities'. Accounting in Europe, 5(1), 27-47.

[32] Business, S. (2014). The role of accounting services and impact on small medium enterprises (SMEs) performance in manufacturing sector from East Coast Region of Malaysia: A conceptual paper. Procedia-Social and Behavioral Sciences, 115, 54-67.

[33] Hair, J., Hollingsworth, C. L., Randolph, A. B., \& Chong, A. Y. L. (2017). An updated and expanded assessment of PLS-SEM in information systems research. Industrial Management \& Data Systems.

[34] Marek, R., Jin, J., Goode, T. D., Giustino, T. F., Wang, Q., Acca, G. M., ... \& Lynch, J. W. (2018). Hippocampus-driven feed-forward inhibition of the prefrontal cortex mediates relapse of extinguished fear. Nature neuroscience, 21(3), 384-392.

[35] Hossen, S., Hossain, M. K., Basher, M. K., Mia, M. N. H., Rahman, M. T., \& Uddin, M. J. (2019). Smart nanocarrier-based drug delivery systems for cancer therapy and toxicity studies: A review. Journal of advanced research, 15, 1-18.

[36] Hair, J. F., Ringle, C. M., \& Sarstedt, M. (2011). PLS-SEM: Indeed a silver bullet. Journal of Marketing theory and Practice, 19(2), 139-152.

[37] Henseler, J., Ringle, C. M., \& Sarstedt, M. (2015). A new criterion for assessing discriminant validity in variance-based structural equation modeling. Journal of the academy of marketing science, 43(1), 115-135. 
Adoption of Malaysian Private Entities Reporting Standards (MPERS): Examining the Features of the Standards and Challenges of Implementation

[38] Kock, N., \& Lynn, G. (2012). Lateral collinearity and misleading results in variance-based SEM: An illustration and recommendations. Journal of the Association for information Systems, 13(7).

[39] Fornell, C. and Cha, J. (1994), "Partial least squares", in Bagozzi, R.P. (Ed.), Advanced Methods of Marketing Research, Blackwell, Cambridge.

[40] Lekhanya, L. M. (2013). Cultural influence on the diffusion and adoption of social media technologies by entrepreneurs in rural South Africa. The international business \& economics research journal.

[41] DeFond, M. L. (2010). Earnings quality research: Advances, challenges and future research. Journal of Accounting and Economics, 50(2-3), 402-409.

[42] Li, C. (2010). Groundswell. Winning in a world transformed by social technologies. Strategic Direction.

[43] Daske, H., Hail, L., Leuz, C., \& Verdi, R. (2013). Adopting a label: Heterogeneity in the economic consequences around IAS/IFRS adoptions. Journal of accounting research, 51(3), 495-547. 